DOI: $10.20396 /$ cel.v62i0.8655883

(c) $(1) \Theta$

\title{
ALÇAMENTO TEMPORAL EM COMPLEMENTOS INFINITIVOS DO PORTUGUÊS
}

\author{
(TEMPORAL RAISING IN PORTUGUESE NON-FINITE \\ COMPLEMENTS)
}

\author{
MARCELO FERREIRA ${ }^{1}$
}

\begin{abstract}
RESUMO: Este artigo discute aspectos da interação entre tempo e modalidade relacionados à interpretação de orações com verbos modais no português. Defende-se que o complemento de todos os verbos modais pode hospedar um operador de futuro que se manifesta na morfologia do próprio verbo. Propõe-se também que o complemento dos modais epistêmicos hospeda uma projeção de tempo cujo núcleo é alçado para a oração principal, novamente se manifestando morfossintaticamente como desinência do verbo. Por fim, contrasta-se o comportamento dos complementos infinitivos dos verbos modais epistêmicos com o de verbos de atitude proposicional, notando que, para esses últimos, não há a possibilidade de um tempo referencial livre e nem a de alçamento para a oração principal, resultando em um perfil morfossemântico mais transparente.
\end{abstract}

Palavras-chave: verbos modais; tempo; modalidade; infinitivos.

ABSTRACT: The article discusses some aspects of the interaction between tense and modality in the interpretation of modal verbs in Portuguese. It is argued that the complement of all modal verbs can host a future operator that is pronounced as a suffix attached to the verb. It is also argued that the complement of epistemic modals hosts a tense head (present or past) which is raised to the main clause and also pronounced as an affix on the verb. Non-finite complements of epistemic modals are contrasted with non-finite complements of verbs of attitude, which do not instantiate a referential tense or allow temporal raising, resulting in a more transparent morpho-semantic profile.

Keywords: modal verbs; tense; modality; infinitives.

\section{INTRODUÇÃ̃O ${ }^{2}$}

Verbos modais são notórios por sua flexibilidade em atrelar as noções de possibilidade e necessidade a uma variedade de domínios:

(1) Pedro tem que se alistar nas forças armadas. Ele completa 18 anos esse ano.

${ }^{1}$ Universidade de São Paulo (USP), São Paulo, SP, Brasil..ferreira10@usp.br

Orcid: https://orcid.org/0000-0002-8879-361X

${ }^{2}$ Gostaria de agradecer aos pareceristas anônimos da revista pelos comentários, críticas e sugestões que fizeram e ao CNPq pelo auxílio financeiro na forma de bolsa de produtividade em pesquisa concedida ao autor. 
(2) João deve/pode estar em casa. A luz do quarto dele está acesa.

Esses exemplos ilustram o que se pode chamar de variabilidade no deslocamento modal. No caso de (1), devemos nos deslocar para situações em que as leis são respeitadas, enquanto em (2), devemos nos deslocar para situações compatíveis com as evidências de que o falante dispõe. No primeiro caso, falamos de uma leitura deôntica. No segundo caso, falamos de uma leitura epistêmica. Outros sabores modais estão vinculados a desejos, metas e desdobramentos futuros, dando origem a leituras buléticas, teleológicas, metafísicas, respectivamente:

(3) João tem que conseguir esse emprego. Seria tão bom pra ele!

(4) Para chegar ao seu destino, você deve usar o metrô.

(5) No intervalo, a partida estava empatada e o Brasil ainda podia vencer o jogo.

Salienta-se, em particular, o fato de que um mesmo verbo pode estar a associado a várias leituras:

(6) João deve permanecer no país este mês. Caso contrário, estará violando sua liberdade condicional.

(7) João deve permanecer no país este mês. Até onde eu sei, ele não tem nenhum show marcado no exterior.

Essa flexibilidade distingue verbos modais de verbos de atitude proposicional, como acreditar e querer, em que o tipo de deslocamento modal é determinado lexicalmente:

(8) João acredita que permanecerá no país este mês.

(9) João quer permanecer no país este mês.

Nesses casos, o conteúdo da oração subordinada que serve de complemento aos verbos da oração principal deve estar em conformidade com as crenças do sujeito (João), no caso do verbo acreditar, ou com seus desejos, no caso do verbo querer.

A possibilidade de diferentes interpretações (ou leituras) de verbos como poder, dever, ter que é comum a várias línguas (ainda que haja variação intra e trans-linguística a esse respeito) e não parece uma boa ideia basear sua análise em um mero caso de ambiguidade lexical. Na esteira dos trabalhos pioneiros de Angelika Kratzer (KRATZER 1981, 1991), tornou-se padrão assumir uma semântica monossêmica para os verbos modais, acoplada a uma dependência contextual. Dessa forma, a natureza do deslocamento modal não é pré-fixada semanticamente, mas sim determinada pelo contexto de fala. Um desafio a essa uniformidade semântica vem da interação entre tempo e modalidade. Após os trabalhos seminais de Kratzer, tem sido notado que diferentes sabores modais 
implicam em diferentes perfis morfossintáticos, gerando assimetrias entre modais lidos epistêmica e não epistemicamente (ver, dentre outros, CINQUE 1999, CONDORAVDI 2002, HACQUARD 2006):

(10) Antigamente trabalhadores podiam se aposentar aos 50, hoje não podem mais.

(11) Pedro não compareceu à reunião da semana passada. Ele devia estar doente.

Como se nota em (10), a marcação temporal no verbo modal com leitura deôntica (não epistêmica, portanto) indica o tempo da perspectiva modal, ou seja, o tempo das leis em questão. Já em (11), a mesma marcação morfológica indica, não o tempo da perspectiva, mas sim o da proposição modalizada. Ou seja, (11) diz que, de acordo com as evidências disponíveis no momento de fala, é provável que o Pedro estivesse doente no dia da reunião. Como mostraremos adiante, esse é um padrão robusto que desafia o tratamento unificado de Kratzer, como já salientado por Hacquard.

Este breve artigo discute essas questões usando o português como material empírico. Defende-se que o complemento de todos os verbos modais pode hospedar um operador de futuro que se manifesta na morfologia do próprio verbo. Propõe-se também que o complemento dos modais epistêmicos hospeda uma projeção de tempo cujo núcleo é alçado para a oração principal, novamente se manifestando morfossintaticamente como desinência do verbo. Por fim, contrastase o comportamento dos complementos infinitivos dos verbos modais epistêmicos com o de verbos de atitude proposicional, notando que, para esses últimos, não há a possibilidade de um tempo referencial livre e nem a de alçamento para a oração principal, resultando em um perfil morfossemântico mais transparente. $\mathrm{O}$ artigo está organizado da seguinte forma: nas seções 2 e 3, delineamos os pressupostos teóricos de nossa abordagem, que está baseada em uma ontologia que inclui intervalos de tempo e mundos possíveis. Semanticamente, nosso ponto de partida será uma teoria referencial do tempo e uma semântica modal baseada em quantificação sobre mundos possíveis. Na seção 2, traçamos um panorama da teoria referencial do tempo (KLEIN 1994, KRATZER 1998), ignorando elementos modais. Na seção 3, apresentamos a semântica de mundos possíveis aplicada ao significado dos verbos modais (em uma versão simplificada de KRATZER 1981, 1991), desta vez ignorando elementos temporais. Já nas seções 4 e 5, que são o núcleo do artigo, olhamos para a interação entre os ingredientes temporais e modais vistos separadamente nas seções anteriores e propomos soluções híbridas para alguns casos complexos, nos quais há um aparente descompasso entre o perfil morfossintático superficial da sentença e a interpretação de seus elementos temporais e modais. A seção 6 é uma breve conclusão.

\section{SEMÂNTICA TEMPORAL (SEM MODALIDADE)}

Conforme já mencionado anteriormente, a base teórica no domínio temporal sobre a qual este artigo se assenta é a teoria referencial do tempo. Apresentamos 
a seguir uma versão dessa teoria que ilustraremos ao final com os tempos verbais indicativos do português.

Limitando, por ora, nossa atenção a questões temporais, vamos assumir, para efeitos de apresentação, um esqueleto frasal simplificado em que sintagmas verbais (VP/vP) são dominados por sintagmas aspectuais (AspPs), que por seu turno são dominados por sintagmas temporais (TPs):

$$
\left[_{\mathrm{TP}} \mathrm{T}\left[\left[_{\mathrm{AspP}} \operatorname{Asp}[\mathrm{VP} / \mathrm{vP} \ldots \mathrm{V} \ldots]\right]\right]\right.
$$

Em uma semântica baseada em intervalos de tempo, podemos assumir que projeções verbais denotam conjuntos (ou suas funções características) de intervalos correspondendo intuitivamente ao tempo da ocorrência de uma situação (evento ou estado) descrita pelo verbo e seus argumentos: ${ }^{3}$

\section{$\llbracket[v P / V P$ “João morar em Londres" $] \rrbracket=\lambda i$.’’João mora em Londres em" $i$}

No caso acima, a denotação do sintagma verbal caracteriza o conjunto dos intervalos de tempo em que o João morou, mora ou morará em Londres.

Núcleos aspectuais são operadores que ligam existencialmente esse argumento temporal dos verbos, relacionando-o a um outro intervalo de tempo (frequentemente denominado de intervalo de referência). Seguindo KLEIN 1994 e KRATZER 1998, postulamos três possíveis núcleos Asp: ${ }^{4}$

(15) $\llbracket$ imperfectivo $\rrbracket=\lambda P . \lambda i . \exists i^{\prime}\left[i \subseteq i^{\prime} \& P\left(i^{\prime}\right)\right]$

(16) $\llbracket$ perfeito $\rrbracket=\lambda P . \lambda i . \exists i^{\prime}\left[i^{\prime}<i \& P\left(i^{\prime}\right)\right]$

Em palavras, o aspecto perfectivo situa o tempo de uma situação no interior de um dado intervalo. $\mathrm{O}$ aspecto imperfectivo faz o inverso, situando um intervalo de tempo dentro do tempo de uma situação, e com isso veiculando a ideia de uma ação em curso em um dado momento. Por fim, o aspecto perfeito indica que o tempo de uma situação é anterior a um certo intervalo. A aplicação desses operadores aspectuais à denotação de um sintagma verbal resulta em uma propriedade de intervalos de tempo:

(17) $\llbracket$ perfectivo+J.morar em Londres $\rrbracket=\lambda i \cdot \exists i^{\prime}\left[i^{\prime} \subseteq i\right.$ \& J.mora em L.em i' $]$

\footnotetext{
${ }^{3}$ Usamos aqui o termo situação para nos referir de forma genérica a estados e ações de todos os tipos. Usamos a forma infinitiva para indicar um verbo despido de suas propriedades tempo-aspectuais. Já a preposição em usada na metalinguagem em (13) deve ser entendida como indicando o intervalo correspondente à duração exata da situação descrita em VP.

${ }^{4}$ Tanto Klein quanto Kratzer se valem de uma semântica baseada em eventos para o significado de sintagmas verbais. Aqui optamos por uma semântica baseada em intervalos, por razões de simplicidade. Nada importante, entretanto, vincula-se a essa escolha.
} 
(18) 〔imperfectivo+J.morar em Londres $\rrbracket=\lambda i . \exists i^{\prime}\left[i \subseteq i^{\prime} \&\right.$ J.mora em L.em i' $]$

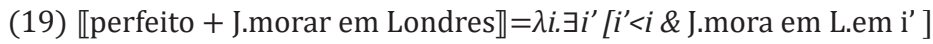

No primeiro caso (perfectivo), o resultado são intervalos de tempo que contém uma situação do João morar em Londres. No segundo (imperfectivo), temos intervalos contidos em uma situação do João morar em Londres, ou seja, intervalos em que uma tal situação estava em curso. Já no terceiro caso (perfeito), temos intervalos que sucedem uma situação do João morar em Londres.

Esse intervalo de tempo que o aspecto relaciona com o tempo de uma situação é fornecido pelo núcleo T. A ideia é que núcleos temporais hospedam pro-formas referenciais que denotam intervalos de tempo, semelhantes às que se assume com pronomes pessoais e indivíduos no domínio nominal, nas linhas sugeridas originalmente por PARTEE (1973) (ver também HEIM 1994 e KRATZER 1998):

(20) $\llbracket$ presente $\rrbracket^{g}=m f$ (o momento de fala)

(21) $\llbracket$ pretérito $\rrbracket_{i}^{g}=g(i)$, se $g(i)<$ momento de fala / indefinido, nos demais casos

O tempo presente, como expresso em (20), denota o próprio momento de fala. Já o pretérito tem sua natureza de variável codificada na forma de uma denotação dependente de uma atribuição $(g)$ de valores a variáveis. Seu caráter indexical, indicando dependência em relação ao momento de fala, é codificado na forma de pré-condições sobre essas denotações. Assim, o pretérito só pode denotar intervalos que precedem o momento de fala. Qual intervalo é denotado depende de outros aspectos do contexto de fala, modelados em (21) com o auxílio de um índice numérico $(i)$.

Esses núcleos temporais servirão de argumento às funções denotadas pela projeção aspectual AspP, que vimos em (17)-(19). O resultado será uma proposição (ou, equivalentemente, condições de verdade). Ilustramos abaixo a combinação do tempo pretérito com os três núcleos aspectuais, o que resulta nas três formas de pretérito do modo indicativo da gramática do português: ${ }^{5}$

(22) 【João morou em Londres $\rrbracket^{g}=1$ sse $\exists i^{\prime}\left[i^{\prime} \subseteq\right.$ g(i) \& J. mora em L.em $\left.i^{\prime}\right]$

(23) 【João morava em Londres $\rrbracket^{g}=1$ sse $\exists i^{\prime}\left[\mathrm{g}(i) \subseteq i^{\prime} \quad \&\right.$ J. mora em L.em i' ]

(24) 【João tinha morado em Londres $\rrbracket^{g}=1$ sse $\exists i^{\prime}\left[i^{\prime}<\mathrm{g}(i) \&\right.$ J. mora em L.em $\left.i^{\prime}\right]$

Assume-se ainda um operador de futuro, cujo papel temporal guarda certa semelhança com o aspecto perfeito, porém na direção contrária, indicando posterioridade em relação a um intervalo:

${ }^{5}$ Usaremos $g(i)$ para referir a um intervalo pretérito contextualmente saliente e a abreviação sse no lugar de se, e somente se para expressar condições de verdade. 
(25) $\llbracket$ futuro $\rrbracket=\lambda P . \lambda i \cdot \exists i^{\prime}\left[i^{\prime}>i \& P\left(i^{\prime}\right)\right]$

Esse operador pode juntar-se tanto a um $\mathrm{T}$ presente (futuro do presente) quanto a um T pretérito (futuro do pretérito): ${ }^{6}$

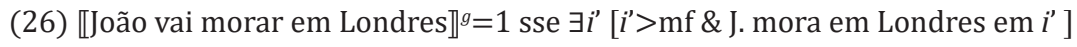

(27) 【João ia morar em Londres $\rrbracket^{g}=1$ sse $\exists i^{\prime}\left[i^{\prime}>g(i) \&\right.$ J. mora em Londres em $\left.i^{\prime}\right]$

\section{SEMÂNTICA MODAL (SEM TEMPO)}

Em relação ao domínio da modalidade, vamos adotar uma semântica de mundos possíveis e a proposta de que certas expressões introduzem quantificação restrita sobre esse domínio (ver, por exemplo, GAMUT 1991, volume 2). Interessanos, em particular, os verbos modais. Nesse caso, apenas a força quantificacional é codificada lexicalmente, cabendo ao contexto a especificação da restrição. Por exemplo, poder introduz quantificação existencial (possibilidade) enquanto dever e ter que introduzem quantificação universal (necessidade). ${ }^{7}$ Sobre a restrição, assumiremos a presença de uma variável livre $R$ (chamada, na lógica modal, de relação de acessibilidade), que nos dará o conjunto de mundos possíveis no qual o argumento (prejacente) do verbo modal é avaliado. ${ }^{8}$ Ilustremos com um exemplo do português:

(28) João tem que se alistar nas forças armadas.

Em sua leitura mais saliente, essa sentença expressa que João se alistar nas forças armadas é uma obrigação legal. Trata-se, pois, de uma interpretação deôntica. Assume-se que sua forma lógica simplificada, a qual serve de entrada ao componente semântico, é a seguinte (elementos temporais ignorados, por enquanto):

(29) [ ter_que ${ }_{\mathrm{R}}$ [ João se alistar nas forças armadas ]]

${ }^{6}$ Apresentamos aqui as formas perifrásticas, mais comuns no português brasileiro coloquial, mas o mesmo se dá com as formas sintéticas, morará e moraria. Note que, do ponto de vista morfológico, as desinências verbais das formas sintéticas, sejam de presente, pretérito ou futuro, evidenciam um sincretismo entre tempo e aspecto, como no sufixo - va em morava, que codifica a combinação pretérito + imperfectivo.

${ }^{7}$ As diferenças de força entre dever, às vezes chamado de modal de necessidade fraca, e ter que, às vezes chamado de modal de necessidade forte, é um tópico complexo e que não abordaremos neste artigo, já que se trata de uma questão ortogonal aos nossos propósitos. Ver, sobre isso, PESSOTTO (2014) e KRATZER ET AL. (2014).

${ }^{8}$ Nossa exposição se mostra mais simples que aquela apresentada nos trabalhos seminais de KRATZER (1981, 1991), em que se usam dois parâmetros contextuais nas definições de possibilidade e necessidade. Esses parâmetros, chamados de base modal e fonte de ordenação, restringem e estruturam o domínio modal, permitindo a definição de certas noções graduais de necessidade e possibilidade. Para o que estamos discutindo neste artigo, isso não será importante. 
A ideia é que a expressão João se alistar nas forças armadas denota uma proposição, identificada como um conjunto de mundos possíveis, servindo de argumento a ter que, interpretado como um operador modal de necessidade. ${ }^{9}$

Com esse mínimo no lugar, imaginemos um cenário em que João seja brasileiro, do sexo masculino, que tenha acabado de completar 18 anos e que as leis nacionais imponham que todo cidadão brasileiro deva se alistar no ano em que completa 18 anos. Neste cenário, (28) é verdadeira. Intuitivamente, a verdade dessa sentença depende de dois aspectos do mundo real: de certas circunstâncias envolvendo João (nascimento, nacionalidade, etc.) e do que a lei, no caso, a lei militar, prescreve (deveres e obrigações, punições, etc.). Esses aspectos estão embutidos na restrição $R$ que nos remete a mundos deonticamente ideais, em que todas as leis são obedecidas. ${ }^{10}$

Caso as leis em questão fossem menos rigorosas, permitindo, mas não obrigando, o alistamento militar, (28) seria falsa. Nesse caso, caberia apenas o uso de um modal de possibilidade (permissão), como poder:

(30) João pode se alistar nas forças armadas.

Semanticamente, o papel dos verbos modais é avaliar a proposição que lhe serve de argumento nos mundos selecionados pela relação de acessibilidade, verificando se a mesma é verdadeira em todos (necessidade) ou ao menos em alguns (possibilidade) desses mundos:

$$
\begin{aligned}
& \llbracket \text { ter que } \rrbracket_{\mathrm{R}} \rrbracket^{w}=\lambda p . \forall w^{\prime}\left[R\left(w, w^{\prime}\right) \rightarrow w^{\prime} \in p\right] \\
& \llbracket \operatorname{poder}_{\mathrm{R}} \rrbracket^{w}=\lambda p . \exists w^{\prime}\left[R\left(w, w^{\prime}\right) \& w^{\prime} \in p\right]
\end{aligned}
$$

O outro tipo de modalidade que nos interessa é a epistêmica, que expressa o que se sabe ou o que se tem disponível como evidência. Nesse caso, cabe também uma análise nos moldes acima. As entradas lexicais em (31) e (32) permanecem intactas e $R\left(w, w^{\prime}\right)$ passa a representar os mundos $w^{\prime}$ consistentes com o conhecimento ou as evidências disponíveis em $w$, o mundo de avaliação da oração principal.

(33) João pode/tem que estar em casa (a luz da sala está acesa). [ pode $_{R} /$ ter_que $_{R}$ [ João estar em casa ]]

\footnotetext{
${ }^{9}$ Estamos assumindo que um requerimento da sintaxe do português faz com que o sujeito João se mova de sua posição original para a posição pré-verbal em que é pronunciado. Tal movimento, entretanto, não teria consequências semânticas nesse caso.

${ }^{10}$ Nos termos kratzerianos, fala-se, nesse caso, em uma base modal circunstancial, que restringe inicialmente a quantificação a mundos que compartilham com o mundo real certas circunstâncias (fatos) e uma fonte de ordenação deôntica, que estabelece um ideal que permite ranquear os mundos previamente selecionados pela base modal de acordo com esse ideal.
} 


\section{TEMPO E MODALIDADE NOS VERBOS MODAIS}

Como se pode notar na apresentação das seções anteriores, tempo e modalidade foram tratados como dois domínios separados, negligenciando questões modais quando se falou de tempo e questões temporais quando se falou de modalidade. Por exemplo, nenhum parâmetro temporal aparece nas denotações dos verbos modais. Isso, entretanto, é duplamente contra-intuitivo: por um lado, obrigações, permissões, evidências e conhecimento mudam com o tempo. O que sabemos hoje não necessariamente coincide com o que sabíamos ontem. Leis também mudam e o que é permitido hoje pode não ter sido no passado. Ou seja, precisamos incorporar o que CONDORAVDI (2002) chamou de perspectiva temporal nos operadores modais. Por outro lado, aquilo que estamos modalizando pode dizer respeito ao passado ou ao futuro. Uma possibilidade epistêmica atual, por exemplo, pode estar relacionada a algo que já ocorreu ou que ainda está em curso. Precisamos, pois, de uma orientação temporal para o argumento (prejacente) dos operadores modais. Isso é particularmente importante para o caso de complementos infinitivos, que não apresentam marcação morfológica temporal aparente.

$\mathrm{O}$ que pode parecer à primeira vista um exercício de rotina tem se mostrado uma tarefa bastante intricada, e é esse o domínio que queremos explorar aqui. Conforme já salientamos na introdução, o português fornece um domínio empírico particularmente fértil e desafiador nessa área, como ilustraremos a seguir, abordando algumas questões espinhosas.

Adicionar ingredientes temporais à semântica kratzeriana dos verbos modais que vimos mais acima na apresentação do quadro teórico é algo relativamente simples. Por exemplo, a versão atemporal da entrada lexical do verbo poder, que repetimos abaixo em (34), pode ser modificada como em (35):

(35) $\llbracket \operatorname{poder}_{\mathrm{R}} \rrbracket^{\mathrm{w}}=\lambda P . \lambda t \exists \mathrm{w}^{\prime}\left[\mathrm{R}\left(\mathrm{w}, \mathrm{w}^{\prime}, t\right) \& \mathrm{w}^{\prime} \in P(t)\right]$

Nessa nova versão, foram acrescentados tanto um argumento temporal $(t)$ ao próprio predicado modal, representando o tempo da possibilidade em questão, quanto um argumento temporal ao prejacente $(P)$, viabilizando sua manipulação pela denotação do verbo modal (ver CONDORAVDI 2002). Para um exemplo como (36) a seguir, em sua leitura epistêmica e com um predicado principal estativo, nada muito interessante ocorre, e podemos assimilar o tempo da possibilidade ao tempo do prejacente, ambos identificados como o momento de fala:

(36) Pedro pode estar em casa (agora).

Dadas as evidências que se tem agora, é possível que Pedro esteja em casa agora.

Nesse caso a interpretação é transparente em relação ao perfil morfossintático da sentença. O verbo modal se encontra no presente e seu complemento, no infinitivo, despido, portanto, de marca temporal. 
Os fatos começam a ficar interessantes quando essa transparência deixa de ser atestada e os ingredientes temporais se misturam aos demais elementos da sentença de maneira não-trivial, desafiando uma abordagem composicional. Compare, por exemplo, (37) e (38):

(37) (No futuro), jovens de 16 anos poderão dirigir (as leis mudarão).

(38) Pedro poderá participar da festa no final de semana (a mãe dele já deixou).

Em ambos os casos, o verbo modal se encontra no futuro e o prejacente no infinitivo (como, aliás, sempre ocorrerá com esses verbos modais). A interpretação em ambos é deôntica, remetendo a certas leis. Entretanto, em (37), temos leis futuras, regulando um evento que será, então, presente, enquanto em (38), temos leis atuais regulando um evento futuro.

O exemplo em (37) é a princípio o mais simples de se analisar semanticamente com a nova entrada lexical apresentada em (35). Basta assumir que o operador de futuro domina o verbo modal, como a morfologia nos faz esperar:

(39) [ FUTURo [ pode ${ }_{\text {deon }}$ [ jovens de 16 anos dirigir ]]]

Nesse caso, o intervalo introduzido pelo futuro saturará o argumento temporal do verbo modal e a forma infinitiva do predicado principal será interpretada como simultânea a esse futuro. Em outras palavras, o operador de futuro terá escopo sobre o verbo modal.

Já no exemplo visto em (38), a relação de escopo parece se inverter, com o futuro operando sob o verbo modal:

(40) $\left[\right.$ pode $_{\text {deon }}$ [ FUTURo [ Pedro participar da festa ]]]

Essa conclusão, entretanto, é questionável. Apesar de a permissão já ter sido concedida e estar em vigor no momento de fala, imagina-se que ela perdurará até o momento do evento subordinado, ou seja, a participação na festa. Mais convincentes são exemplos como (41), em que se enfatiza a perspectiva deôntica presente, questionando-se, entretanto, se as obrigações permanecerão como estão:

(41) Talvez a chefe do Pedro venha a liberá-lo, mas, no momento, ele terá que trabalhar no final de semana.

(42) Talvez a chefe do Pedro venha a liberá-lo, mas, no momento, ele não poderá participar da festa no final de semana.

Nesse caso, atribuir uma perspectiva futura aos modais ter que e poder parece incoerente, dada a dúvida levantada no discurso imediatamente precedente. 
A situação se complica um pouco mais quando observamos que essa marcação de futuro é opcional e que uma interpretação semelhante poderia ser obtida com o modal no presente, como ilustrado abaixo: ${ }^{11}$

(43) Talvez a chefe do Pedro venha a liberá-lo, mas, no momento, ele tem que trabalhar no final de semana.

(44) Talvez a chefe do Pedro venha a liberá-lo, mas, no momento, ele não pode participar da festa no final de semana.

Para dar conta de todas essas possibilidades, vamos assumir que o prejacente de um modal deôntico pode conter uma projeção sintática que hospeda operadores de futuro (ABUSCH 1998, WURMBRAND 2014).

(45) $\ldots\left[\right.$ VPP $_{\text {modal }}\left[{ }_{\text {deon }}\right.$ FutP FUTURO ... VP ... $\left.]\right]$

Nossa proposta é que o núcleo dessa projeção pode se incorporar morfologicamente ao verbo modal, sendo, nesse caso, pronunciado como uma desinência de futuro, ou permanecer in situ, sem reflexos fonológicos:

(46) Pedro poderá participar da festa

... [ ${ }_{\mathrm{VP}}$ poder+FUTURo $_{\mathrm{i}}\left[\right.$ FutP $_{\mathrm{i}} \ldots$ participar $\left.\left.\ldots\right]\right]$

(47) Pedro pode participar da festa.

... [ [ VP $\operatorname{poder}\left[{ }_{\text {FutP }}\right.$ FUTURO ... participar ... ]]

Note-se que, procedendo dessa forma, esquivamo-nos de embutir na própria entrada lexical do verbo modal o deslocamento temporal futuro, o que teria resultado em uma denotação como a abaixo:

(48) $\llbracket \operatorname{poder}_{\mathrm{R}} \rrbracket^{\mathrm{w}}=\lambda P . \lambda t \exists w^{\prime}\left[R\left(w, w^{\prime}, t\right) \& \exists t^{\prime}>\mathrm{t}\left[w^{\prime} \in P\left(t^{\prime}\right)\right]\right.$

Tal entrada implicaria na orientação futura de todos os usos de um verbo modal, o que não estaria de acordo com os fatos. Se essa orientação parece correta para as interpretações deônticas, definitivamente ela não é observada em interpretações epistêmicas, veiculadas através do uso das mesmas formas verbais:

${ }^{11}$ Essa opcionalidade nos remete a uma outra envolvendo o futuro perifrástico formado com o auxiliar $i r$ seguido de infinitivo:

(i) a. Pedro vai participar da festa amanhã.

b. Pedro irá participar da festa amanhã.

Não nos parece haver diferenças significativas entre as duas versões acima e algo semelhante pode ser dito do par anterior envolvendo poder. Seria essa marcação extra de futuro algo de natureza expletiva e, portanto, sem valor semântico? Ou é possível encontrar uma explicação para sua presença, mantendo uma análise uniforme em que o futuro sempre contribui da mesma forma para a composição do significado? Deixaremos esse aparente caso de variação em aberto, bem como as indagações que ele suscita. 
(49) a. Pode estar chovendo (agora).

b. Pode ter chovido (ontem).

Nesses casos, não há qualquer deslocamento futuro e os prejacentes infinitivos estão ancorados no momento da possibilidade (presente), cabendo aos operadores aspectuais neles contidos (progressivo e perfeito) os respectivos deslocamentos temporais de superposição e precedência. A ideia, portanto, é que algo semelhante aconteça com os casos de interpretação epistêmica com orientação futura:

(50) Pode chover (amanhã).

Aqui teríamos um operador futuro encabeçando o prejacente, sendo a única diferença em relação aos exemplos em (49), a possibilidade de sua não realização fonológica. Como nos casos de modalidade deôntica, quando há uma marcação, ela ocorre como desinência no próprio verbo:

(51) Poderá chover (amanhã).

Note que, mesmo em casos como (49), há a possibilidade de orientação futura:

(52) a. Pode estar chovendo (amanhã).

b. Pode ter chovido (quando você acordar).

(53) a. Poderá estar chovendo (amanhã).

b. Poderá ter chovido (quando você acordar).

Nada de novo precisa ser dito em relação a isso, a não ser que o operador de futuro, quando parte do prejacente, localiza-se em uma posição estruturalmente superior à dos operadores aspectuais de progressivo e de perfeito, e com a já vista possibilidade de incorporação ao verbo modal. (52) e (53) teriam, portanto, as estruturas em (54) e (55), respectivamente:

(54) ... [ [ ${ }_{\mathrm{VP}}$ modal $\left[_{\mathrm{FutP}}\right.$ FUTURO $\left[_{\mathrm{AspP}}\right.$ PERF/PROG VP ]]]

(55) $\ldots .$. VVP $_{\mathrm{VP}}$ modal+ FUTURO $_{\mathrm{i}}\left[\mathrm{FutP}_{\mathrm{i}} \mathrm{t}_{\mathrm{AspP}}\right.$ PERF/PROG VP $\left.\left.]\right]\right]$

Pode-se traçar um paralelo entre o que estamos vendo acima no domínio temporal e estruturas de alçamento no domínio nominal. Nessas, sujeitos de certas orações infinitivas aparecem superficialmente como sujeitos da oração principal:

(56) $\left[\right.$ Pedro $_{i}$ parece $\left[\mathrm{t}_{\mathrm{i}}\right.$ ter cometido o crime $\left.]\right]$

Talvez ainda mais sugestivos, dada a não referencialidade do futuro, sejam casos envolvendo DPs quantificadores: 
Essa sentença admite uma interpretação em que não há um suspeito em particular. Há apenas evidências de que o criminoso seja estrangeiro. Nesse caso, o sintagma indefinido que aparece na posição de sujeito da oração principal é interpretado como se estivesse na oração subordinada, sob o escopo do predicado parecer.

Podemos manter, assim, o espírito da semântica kratzeriana para a flexibilidade de usos dos verbos modais, sem apelo a ambiguidades e limitandonos à escolha de relações de acessibilidade (bases modais e fontes de ordenação) contextualmente salientes.

Há apenas uma diferença entre o perfil temporal das interpretações epistêmicas e deônticas, sobre a qual voltaremos a falar na próxima seção. Tratase do fato de que, diferentemente do que vimos para a interpretação deôntica, a interpretação epistêmica não admite perspectiva futura. Isso significa que mesmo exemplos como (51), com o verbo modal no futuro, não possuem uma leitura de acordo com a qual evidências disponíveis em um momento futuro $t$ indicarão a possibilidade de chuva naquele momento $t$. Essa assimetria é inesperada e a ela voltaremos mais adiante.

Por fim, é importante ter em mente que até aqui não estamos postulando a presença de tempo referencial no prejacente de nenhum verbo modal. Lembremos o que vimos na seção 2: a aplicação do operador de futuro, bem como a dos operadores aspectuais, a seus argumentos verbais resulta em uma propriedade de intervalos de tempo, que, em orações finitas, é saturada por uma pro-forma temporal -- pretérita ou presente -- resultando, aí sim, em uma proposição. Entretanto, colocaremos em disputa, já na próxima seção, essa ausência de tempo (T) no prejacente dos modais.

\section{TEMPO REFERENCIAL SOB VERBOS MODAIS}

Nesta seção, exploraremos a ideia que o prejacente de um verbo modal pode hospedar algum núcleo temporal referencial (pretérito ou presente), a despeito da não marcação de tempo nas formas infinitivas. Para termos um caso convincente a esse respeito, precisamos de exemplos em que a referência temporal do prejacente não coincida com o tempo da modalidade atrelada ao verbo modal. Nossa discussão está baseada em MENDES (2019), de onde adaptamos os exemplos e contextos a seguir.

Comecemos com interpretações epistêmicas. Considere, por exemplo, a seguinte situação: há alguns meses atrás, Pedro foi demitido por sua chefe em razão de ter chegado atrasado ao trabalho diversas vezes, o que ela atribuiu a seu descaso com o emprego. Muito recentemente, entretanto, ela ouviu dizer de fonte confiável que Pedro estava enfrentando sérios problemas de saúde na época. Baseada nisso, está pensando, agora, em reconsiderar sua decisão. Nesse contexto, tanto (58) quanto (59) podem ser usadas pela chefe para expressar seu estado mental atual a respeito daqueles atrasos: 
(58) É possível (provável) que Pedro estivesse doente.

(59) Pedro podia (devia) estar doente.

Em ambos os casos, repetimos, temos modalidade epistêmica. Comecemos com (58), em que tanto o predicado principal quanto o subordinado são formas finitas, trazendo um perfil morfossemântico mais transparente. Temos um tempo presente na oração principal e um tempo pretérito na oração subordinada, o que está em total harmonia com a interpretação da sentença: possibilidade epistêmica presente a respeito de algo ocorrido no passado. É (59), entretanto, que nos interessa. Temos, agora, tempo pretérito na oração principal e uma forma infinitiva (e sem aspecto perfeito) na oração subordinada. ${ }^{12}$ Curiosamente, (59) pode ser interpretada como (58): possibilidade presente sobre fato pretérito, em uma total desarmonia com seu perfil morfossintático superficial.

Adotando uma análise proposta em STOWELL (2004), postularemos que o tempo pretérito que aparece junto ao verbo modal se origina em seu prejacente, incorporando-se ao mesmo via alçamento. Para isso, entretanto, precisamos postular um tempo referencial pertencente ao complemento do verbo modal:

(60) $\ldots\left[\left[_{\mathrm{VP}}\right.\right.$ modal $\left[{ }_{\mathrm{TP}}\right.$ PRETéRITO $\left.\left._{\mathrm{i}} \ldots \mathrm{VP}\right]\right] \Rightarrow \ldots\left[{ }_{\mathrm{VP}}\right.$ modal+ PRETéRITO $\left.{ }_{\mathrm{i}}\left[_{\mathrm{TP}} \mathrm{t}_{\mathrm{i}} \ldots \mathrm{VP}\right]\right]$

Cabe aqui também o paralelo com estruturas de alçamento envolvendo argumentos nominais referenciais que vimos na seção anterior:

(61) João parece [ $\mathrm{t}_{\mathrm{i}}$ estar desempregado ]

Nesse caso, o sujeito João está conectado semanticamente com o predicado subordinado estar desempregado, resultando em uma interpretação semelhante à de (62):

(62) Parece que João está desempregado.

E quanto à perspectiva temporal dos verbos modais nesse tipo de estrutura? Limitemo-nos, por ora, à modalidade epistêmica. Assumiremos que a perspectiva assume um valor default, que, no caso de orações principais, corresponde ao momento de fala. Isso confere aos exemplos em questão uma perspectiva presente.

Exemplos análogos aos que vimos acima podem ser construídos com prejacentes contendo infinitivos perfeitos (ter+particípio). Também nesse caso, o

\footnotetext{
${ }^{12}$ Mais especificamente, temos, nesse exemplo, o verbo modal no pretérito imperfeito (podia). É interessante notar que o uso do pretérito perfeito (pôde) não é compatível com leituras epistêmicas. Uma sentença como João pôde estar na reunião, por exemplo não pode ser lida como (59), admitindo apenas leituras não epistêmicas, indicando algo como ter a oportunidade ou permissão para estar na reunião. Deixaremos em aberto esta importante questão a respeito da incompatibilidade entre verbos modais no pretérito perfeito e leituras epistêmicas.
} 
tempo pretérito que aparece marcando o verbo modal é interpretado como tempo de seu complemento, gerando uma leitura de pretérito mais que perfeito:

(63) Pedro podia (devia) já ter adoecido (quando ele foi demitido).

Nesse caso, temos a seguinte paráfrase finita:

(64) É possível (provável) que Pedro já tivesse adoecido (quando ele foi demitido).

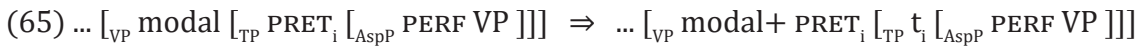

Podemos, inclusive, estender a abordagem acima para modais epistêmicos no presente:

(66) Pode (deve) estar chovendo.

(67) $\ldots\left[\left[_{\mathrm{VP}} \operatorname{modal}\left[{ }_{\mathrm{TP}}\right.\right.\right.$ PRES $_{\mathrm{i}}\left[{ }_{\mathrm{AspP}}\right.$ PROG VP $\left.\left.]\right]\right] \Rightarrow \ldots\left[\mathrm{VP}\right.$ modal+ PRES $\left[_{\mathrm{TP}} \mathrm{t}_{\mathrm{i}}\left[_{\text {AspP }}\right.\right.$ PROG VP $\left.\left.]\right]\right]$

Chegaríamos, assim, a uma uniformização no tratamento dos modais epistêmicos: eles tomam um complemento proposicional que inclui uma projeção de tempo, a qual hospeda uma pro-forma temporal que pode ser alçada para a oração principal, aparecendo na superfície como uma desinência verbal. Sobre a perspectiva temporal, assumimos tratar-se sempre de uma ancoragem no momento de fala, o que condiz com a ideia de que os modais não estão cobertos por uma projeção TP encabeçada por um tempo. Voltaremos a esse ponto logo a seguir. ${ }^{13}$

Passando, agora, a interpretações não epistêmicas, modais com interpretação deôntica se comportam de maneira diferente em relação ao perfil morfossemântico que estamos analisando. Suas desinências temporais são interpretadas em relação ao tempo da modalidade, influenciando assim a perspectiva temporal. Já a orientação temporal do prejacente toma sempre como momento de referência o próprio tempo da modalidade. Dessa forma, modais no passado e no presente terão perspectiva passada e presente, respectivamente, com a orientação do prejacente sendo a mesma, sempre relativizada ao tempo da modalidade:

(68) Maria pode chegar tarde em casa (a mãe dela deixa).

(69) Maria podia chegar tarde em casa (a mãe dela deixava).

Em (68), regras atuais permitem que Maria chegue (no presente/futuro) tarde em casa. Em (69), regras passadas permitiam que Maria chegasse (naquela época) tarde em casa.

Essa dependência entre o momento de referência do prejacente e o tempo (orientação) da modalidade indica que não há tempo referencial livre no prejacente,

${ }^{13}$ Ver VON FINTEL e GILLES (2008), e RULLMANN e MATTHEWSON (2018) para vozes dissonantes. Ver também LACA (2010) para discussão relevante. 
diferindo assim do que vimos no caso das interpretações epistêmicas. Além disso, a transparência semântica da marcação temporal no verbo modal e a correspondente ausência da indexicalidade vista na orientação temporal epistêmica indicam que o verbo modal está coberto por uma projeção temporal quando associado a uma interpretação deôntica.

Se tudo isso estiver no caminho certo, temos os seguintes esqueletos estruturais simplificados para as duas classes de modais:

(70) $\left[\right.$ Modal $\left._{\text {epis }}\left[{ }_{\mathrm{TP}} \mathrm{T}[\mathrm{FutP} / \mathrm{AspP} / \mathrm{VP} \cdots]\right]\right]$

(71) $\left[_{\mathrm{TP}} \mathrm{T}\left[_{\text {FutP } / \text { AspP }} \ldots\right.\right.$ Modal $\left._{\text {deon }}\left[{ }_{\text {FutP } / \mathrm{NP}} \cdots\right]\right]$

A escolha dos rótulos acima não é fundamental para o ponto que estamos defendendo e poderia ser adaptada para esqueletos oracionais mais articulados, como os propostos em CINQUE (1999). O que realmente nos importa é a posição estrutural relativa entre os modais e as categorias que hospedem os tempos referenciais. Como se vê, e em consonância com o que se vê em CINQUE (1999) (ver também HACQUARD 2006), a interpretação epistêmica está relacionada a uma posição estruturalmente mais alta que as interpretações deônticas. ${ }^{14}$

Semanticamente, haverá diferenças também. Estamos assumindo que TPs denotam proposições, enquanto AspPs (ou projeções dominadas por TPs) denotam propriedades temporais. Dessa forma, a denotação de um verbo modal com interpretação epistêmica toma argumentos e retorna valores diferentes daqueles tomados e retornados pela denotação de um verbos modal com interpretação deôntica. Isso, entretanto, entra em choque com os pressupostos kratzerianos que estamos buscando manter de que os mesmos itens lexicais (os verbos modais) subjazem a todas os sabores modais, sendo as diferenças interpretativas derivadas de dependências contextuais codificadas na forma de relações modais (relações de acessibilidade). HACQUARD (2006) propõe uma solução para esse aparente conflito entre a semântica kratzeriana e a sintaxe cinqueana baseada em uma modalidade dependente de eventos. Já FERREIRA (2018) implementou uma alternativa baseada em uma semântica de intervalos, como a assumida aqui, e na qual relações de acessibilidade atuam como modificadores adverbiais, operando sobre verbos modais uniformes semanticamente.

Não iremos discutir, neste artigo, essa importante e complexa questão, já que isso nos afastaria de nosso objetivo mais central, que é defender a existência de alçamento temporal no complemento de verbos modais: alçamento de tempo referencial no caso de modais epistêmicos e alçamento do operador de futuro, no caso de qualquer modal. Sobre isso, ainda temos algo a dizer, como veremos a seguir.

${ }^{14} \mathrm{Um}$ (a) parecerista anônimo(a) sugere que a projeção sintática que hospeda modais epistêmicos possa ser o local de adjunção das orações introduzidas por porque que conferem à oração principal, mesmo quando não há nela verbos modais, um sabor de inferência e conclusão. É o que se vê, por exemplo, em João está (ou deve estar) em casa, porque a luza do quarto está acesa. Essa é, de fato, uma questão interessante e que merece mais atenção. 


\subsection{Outros infinitivos}

Na seção anterior, vimos razões para assumir que prejacentes infinitivos de modais com leitura epistêmica possuem um tempo de referência cuja denotação é contextualmente determinada:

(72) Pedro podia estar dormindo (na hora do crime).

(73) Pedro podia já ter dormido (na hora do crime).

Em ambos os casos, temos possibilidade presente relacionada a um tempo pretérito. Analisamos esses casos como instâncias de alçamento temporal, em que o núcleo T (pretérito) do prejacente é pronunciado na oração principal, como desinência do verbo modal, mas interpretado em seu complemento, servindo de tempo de referência para os operadores aspectuais.

Nesta seção, gostaríamos de verificar se o mesmo é possível com um outro tipo de complemento infinitivo: o dos verbos de atitude, como acreditar e dizer. Teriam também esses complementos um núcleo $\mathrm{T}$ que pode ser instanciado por um tempo referencial livre?

Primeiramente, precisamos dissociar os dois ingredientes teóricos que vimos nos casos com verbos modais, ou seja, a postulação de um tempo referencial no prejacente e o seu alçamento para a oração principal. Comecemos com esse último. Alçamento temporal não parece possível com verbos de atitude, como atestam exemplos como (74) e (75) a seguir, que devem ser comparados com (72) e (73) acima:

(74) Pedro acreditava estar dormindo.

(75) Pedro acreditava já ter dormido.

Nesses dois exemplos, o tempo do verbo acreditar é, de fato, o tempo da atitude, e o prejacente é interpretado a partir do agora do sujeito nesse tempo. Nenhum dos exemplos pode ser interpretado como uma crença presente sobre um tempo passado. Para tanto, deve-se usar um complemento indicativo no pretérito, subordinado a um verbo no presente:

(76) Pedro acredita que estava dormindo.

(77) Pedro acredita que já tinha dormido.

Esclarecida essa questão, perguntemo-nos sobre a possibilidade de o complemento infinitivo ter um tempo real (não pronunciado) independente do tempo da oração principal. Comecemos com configurações com um tempo presente na oração principal. Concretamente, vejamos a possibilidade de os exemplos em (a) abaixo terem interpretações como as em (b): 
(78) a. Pedro (agora) acredita estar dormindo (na hora do crime).

b. Pedro (agora) acredita que estava dormindo (na hora do crime).

(79) a. Pedro acredita já ter dormido (na hora do crime).

b. Pedro acredita que já tinha dormido (na hora do crime).

(80) a. Pedro (agora) diz estar dormindo (na hora do crime).

b. Pedro (agora) diz que estava dormindo (na hora do crime).

(81) a. Pedro (agora) diz já ter dormido (na hora do crime).

b. Pedro (agora) diz que já tinha dormido (na hora do crime).

Como se pode notar, os exemplos em (a), sejam os como verbo acreditar, sejam os com o verbo dizer, não admitem as interpretações dos complementos finitos em (b).

Passemos, agora, a exemplos com o verbo principal no pretérito:

(82) a. Ontem, Pedro (ainda) acreditava estar dormindo (na hora do crime).

b. Ontem, Pedro (ainda) acreditava que estava dormindo (na hora do crime).

(83) a. Ontem, Pedro acreditava já ter dormido (na hora do crime).

b. Ontem, Pedro acreditava que já tinha dormido (na hora do crime).

(84) a. Ontem, Pedro me disse estar dormindo (na hora do crime).

b. Ontem, Pedro me disse que estava dormindo (na hora do crime).

(85) a. Ontem, Pedro me disse já ter dormido (na hora do crime).

b. Ontem, Pedro me disse que já tinha dormido (na hora do crime).

Permanece o contraste claro entre os pares (a)-(b), indicando que o tempo da oração infinitiva deve mesmo estar vinculado ao agora do sujeito no momento da atitude (o que se chama de leitura de nunc), não podendo permanecer livre e ter uma denotação contextualmente definida. ${ }^{15}$

A conclusão é que para que um $\mathrm{T}$ infinitivo (não flexionado) genuinamente referencial seja licenciado, ele precisa ser alçado para junto de um verbo que possa hospedar flexão de tempo e que não esteja, ele mesmo, conectado a projeções

${ }^{15}$ Alguns falantes, entretanto, admitem as interpretações em (b) para os exemplos em (a), quando o verbo principal está no pretérito, o que pode indicar a possibilidade de um tempo referencial infinitivo nos casos em que há concordância com o tempo da oração principal (ambos seriam pretéritos). Relacionado a isso, é relevante notar que STOWELL (2007), inspirado em HOFFMAN (1976), discute casos do inglês em que um perfeito infinitivo pode funcionar como um mais que perfeito finito, parecendo instanciar um tempo pretérito livre. Eis alguns exemplos discutidos por ele:

(i) He is rumored to have seen her [only once before] [when I met him].

(ii) John is believed to have already left when I met him.

Em ambos os casos, as leituras em questão são facilitadas (ou mesmo licenciadas) pelas expressões adverbias em questão e não parecem se estender para infinitivos não-perfeitos. 
tempo-aspectuais que o dominem. Esse é o caso de verbos modais epistêmicos, como defendemos anteriormente, mas não de verbos de atitude, que, como os modais deônticos, estão cobertos por projeções que determinam a perspectiva temporal da modalidade em questão.

\section{CONCLUSÃO}

Este artigo discutiu aspectos da interação entre tempo e modalidade relacionados à interpretação temporal de verbos modais. Buscou-se mostrar como o trabalho conjunto de uma teoria referencial do tempo com uma semântica de mundos possíveis pode ajudar na explicação de algumas questões relacionadas a certos descompassos entre o perfil morfossintático e a interpretação temporal dessas construções.

Em particular, defendemos que o complemento de todos verbos modais pode hospedar uma projeção de futuro que se manifesta na morfologia do próprio verbo. Defendemos também que o complemento dos modais epistêmicos hospeda uma projeção de tempo e que esse tempo, uma pro-forma referencial, é alçado para a oração principal, novamente se manifestando morfossintaticamente como desinência do verbo. Por fim, contrastamos o comportamento dos complementos infinitivos dos verbos modais epistêmicos com o de verbos de atitude proposicional. Notamos que, para esses últimos, não há a possibilidade de um tempo referencial livre e nem a de alçamento para a oração principal, resultando em um perfil morfossemântico mais transparente. Defendemos que as assimetrias observadas entre modais epistêmicos e modais deônticos, ou entre modais epistêmicos e verbos de atitude, se deve ao fato de o modal epistêmico não estar coberto por uma projeção temporal e por tomar um complemento proposicional e não uma propriedade temporal, como o fazem os modais deônticos e os verbos de atitude.

\section{REFERÊNCIAS}

ABUSCH, D. (1998) Generalizaing tense semantics for future contexts. In Rothstein, S., editor, Events and Grammar, pp. 13-33. Kluwer, Dordrecht.

CINQUE, G. (1999) Adverbs and Functional Heads. Oxford University Press, Oxford.

CONDORAVDI, C. (2002) Temporal interpretation of modals: Modals for the present and for the past. In Beaver, D., Kaufmann, S., Clark, B., \& Casillas, L., editores, The Construction of Meaning, pp. 59-88. CSLI Publications, Stanford, CA.

FERREIRA, M. (2018) Estudos Formais sobre a Semântica Nominal e Verbal do Português. Tese de Livre-Docência. Universidade de São Paulo.

VON FINTEL, K. e GILLES, A. (2008) CIA Leaks. Philosophical Review 117, 77-98. 
HACQUARD, V. (2006) Aspects of modality. Tese de Doutorado, Massachusetts Institute of Technology.

HEIM, I. (1994) Comments on Abusch's theory of tense. In Kamp, H., editor, Ellipsis, Tense, and Questions, pp. 143-170. University of Amsterdam, Amsterdam.

HOFFMAN, T. (1976). Past tense replacement and the modal system. In McCawley, J., editor, Notes from the Linguistic Underground, pp. 85-100. Academic Press, New York.

KLEIN, W. (1994). Time in language. Routledge, London; New York.

KRATZER, A. (1981). The notional category of modality. In Eikmeyer, H. \& Rieser, H., editores, Words, Worlds, and Contexts: New Approaches in Word Semantics, pp. 38-74. de Gruyter, Berlin.

KRATZER, A. (1991). Modality. In von Stechow, A. \& Wunderlich, D., editores, Semantics: An International Handbook of Contemporary Research, pp. 639-650. de Gruyter, Berlin.

KRATZER, A. (1998). More structural analogies between pronouns and tenses. In Proceedings of SALT VIII, pp. 92-110. CLC Publications.

KRATZER, A.; PIRES DE OLIVEIRA, R.; PESSOTTO, A. (2014) Talking about modality - an interview with Angelika Kratzer. ReVEL, especial issue 8.

LACA, B. (2010) On Modal Tenses and Tensed Modals. Paris. Université Paris 8/CNRS, Ms.

MENDES, J. (2019). Interações Modal-temporais no português brasileiro. Dissertação de Mestrado. Universidade de São Paulo

PARTEE, B. (1973). Some structural analogies between tenses and pronouns in English. Journal of Philosophy, 70: 601-609.

PESSOTTO, A. (2014) Epistemic and gradable modality in Brazilian Portuguese: a comparative analysis of poder, dever and ter que. ReVEL, special issue 8 .

RULLMAN, H. e MATTHEWSON, L. (2018) Towards a theory of modal-temporal interaction. Language 94.2, pp. 281-331

STOWELL, T. (2004) Tense and modals. In Guéron, J. \& Lecarme, J., editores, The Syntax of Time, pp. 621--635. MIT Press, Cambridge, MA.

WURMBRAND, S. (2014) Tense and aspect in English infinitives. Linguistic Inquiry, 45(3):403-447.

Recebido: 5/07/2019

Aceito: $12 / 11 / 2019$

Publicado: 30/01/2020 